\title{
Left-sided location is a risk factor for lymph node metastasis of T1 colorectal cancer: a single-center retrospective study
}

\author{
Kenichi Mochizuki $^{1} \cdot$ Shin-ei Kudo $^{1} \cdot$ Katsuro Ichimasa $^{1}$ (1) $\cdot$ Yuta Kouyama $^{1} \cdot$ Shingo Matsudaira $^{1} \cdot$ Yuki Takashina $^{1}$. \\ Yasuharu Maeda ${ }^{1}$ - Tomoyuki Ishigaki ${ }^{1}$ - Hiroki Nakamura ${ }^{1}$ - Naoya Toyoshima ${ }^{1}$ - Yuichi Mori ${ }^{1}$ - Masashi Misawa ${ }^{1}$. \\ Noriyuki Ogata ${ }^{1} \cdot$ Toyoki Kudo $^{1} \cdot$ Takemasa Hayashi $^{1} \cdot$ Kunihiko Wakamura $^{1} \cdot$ Naruhiko Sawada $^{1} \cdot$ Fumio Ishida $^{1}$. \\ Hideyuki Miyachi ${ }^{1}$
}

Accepted: 10 June 2020 / Published online: 16 June 2020

(C) The Author(s) 2020

\begin{abstract}
Purpose Although some studies have reported differences in clinicopathological features between left- and right-sided advanced colorectal cancer (CRC), there are few reports regarding early-stage disease. In this study, we aimed to compare the clinicopathological features of left- and right-sided T1 CRC.

Methods Subjects were 1142 cases with T1 CRC undergoing surgical or endoscopic resection between 2001 and 2018 at Showa University Northern Yokohama Hospital. Of these, 776 cases were left-sided (descending colon to rectum) and 366 cases were right-sided (cecum to transverse colon). We compared clinical (patients age, sex, tumor size, morphology, initial treatment) and pathological features (invasion depth, histological grade, lymphatic invasion, vascular invasion, tumor budding) including lymph node metastasis (LNM).

Results Left-sided T1 CRC showed significantly higher rates of LNM (left-sided $12.0 \%$ vs. right-sided $5.4 \%, P<0.05$ ) and lymphatic invasion (left-sided $32.7 \%$ vs. right-sided $23.2 \%, P<0.05$ ). Especially, the sigmoid colon and rectum showed higher rates of LNM (12.4\% and $12.1 \%$, respectively) than other locations. Patients with left-sided T1 CRC were younger than those with right-sided T1 CRC (64.9 years \pm 11.5 years vs. $68.7 \pm 11.6$ years, $P<0.05$ ), as well as significantly lower rates of poorly differentiated carcinoma/mucinous carcinoma than right-sided T1 CRC $(11.6 \%$ vs. $16.1 \%, P<0.05)$.

Conclusion Left-sided T1 CRC, especially in the sigmoid colon and rectum, exhibited higher rates of LNM than right-sided T1 $\mathrm{CRC}$, followed by higher rates of lymphatic invasion. These results suggest that tumor location should be considered in decisions regarding additional surgery after endoscopic resection.

Trial registration This study was registered with the University Hospital Medical Network Clinical Trials Registry (UMIN 000032733).
\end{abstract}

Keywords $\mathrm{T} 1$ colorectal cancer $\cdot$ Lymph node metastasis $\cdot$ Left-sided colon $\cdot$ Risk factor

\section{Introduction}

Colorectal cancer $(\mathrm{CRC})$ is one of the most common cancers worldwide. In Japan, the incidence and mortality of CRC have increased during the last several decades. CRC is the most

Katsuro Ichimasa

ichitommy14@yahoo.co.jp

1 Digestive Disease Center, Showa University Northern Yokohama Hospital, 35-1 Chigasaki-chuo, Tsuzuki,

Yokohama 224-8503, Japan common cause of cancer death in female and the third most common in male [1]. Moreover, CRC mortality is the fourth highest in male and the third highest in female globally, and the second highest worldwide when considering male and female in total [2]. The differentiation of CRC by anatomical location has received substantial attention. CRC is divided into two sides: left-sided, which is composed of the descending and sigmoid colon and the rectum, and right-sided, containing the cecum and the ascending and transverse colon. Many publications have highlighted differences between left- and right-sided CRC [3-7].

Compared with right-sided CRC, left-sided advanced (T2T4) CRC has the following features: longer overall survival; 
younger patients; higher number of male patients; less mucinous or poorly differentiated histology; less associated with $B R A F$ and APC mutations, microsatellite instability (MSI), and $\mathrm{CpG}$ island methylator phenotype (CIMP); and better response to anti-epidermal growth factor receptor (EGFR) therapies. In addition, apart from having a different embryological origin, the proximal colon from the midgut and the distal colon and the rectum from the hindgut, the left-sided colon displays peculiar differences in its mucosal immunology, probably because of differences in the gut microbiota [8-13].

Many studies have investigated the differences in epidemiology, pathogenesis, genetic alterations, and molecular pathways between left- and right-sided advanced CRC, as well as those that divided the location of CRC into the colon and rectum [14-16]. However, few articles have focused on the differences in early-(T1) stage disease and divided the tumor location into the left- and right-sided colon. Therefore, the present study was designed to evaluate the clinicopathological characteristics between left- and right-sided T1 CRC.

\section{Materials and methods}

\section{Patients}

Between April 2001 and December 2018, a total of $1262 \mathrm{~T} 1$ CRC cases were resected endoscopically or surgically at Showa University Northern Yokohama Hospital, Japan. Written informed consent was obtained from all the patients prior to endoscopy. Our ethics committee approved the study protocol (approval number: 17H107). This study was registered with the University Hospital Medical Network Clinical Trials Registry (UMIN 000032733). Patients who underwent surgery because of a synchronous invasive carcinoma $(n=45)$ and those who were diagnosed with Lynch syndrome $(n=3)$ or ulcerative colitis $(n=6)$ were excluded. In some cases, detailed pathological evaluation was not possible owing to the loss of or damage to the specimen, and thus these were also excluded. Furthermore, we did not include patients who received preoperative chemotherapy or radiotherapy. In total, 1142 cases were included. Of these, 776 cases were left-sided (descending colon to rectum), and 366 cases were right-sided (cecum to transverse colon). We analyzed clinicopathological features including patient age, sex, tumor size, morphology, initial treatment, depth of invasion, histological grade, vascular invasion, lymphatic invasion, tumor budding, and lymph node metastasis (LNM). We classified tumor morphology into three types according to the Paris classification and Kudo's classification: flat type (Ila, laterally spreading tumor), protruded type (Is, Ip, Isp), and depressed type (IIc, IIa+IIc, IIc+IIa, Is+IIc, Ip+IIc). [17] Surgical specimens were used as the standard for the presence of LNM. For patients with endoscopic resection, local lymph node recurrent cases detected by CT or MRI were defined as LNM-positive, regardless of the period. In the endoscopic resection alone group, the mean follow-up period was $41.5 \pm 34.7$ months (Fig. $1)$.

\section{Histological examination}

All resected specimens were retrieved and immediately fixed in a $10 \%$ buffered formalin and were observed with a focus on the pit pattern using a stereomicroscope. They were then cut at the point where the deepest invasion area could be exposed on the cut end surface. The other histological specimens were cut into parallel 2- to 3-mm-thick sections and stained with hematoxylin and eosin (H\&E). Tumor size was measured after
Fig. 1 Study flow chart. CRC, colorectal cancer; ER, endoscopic resection

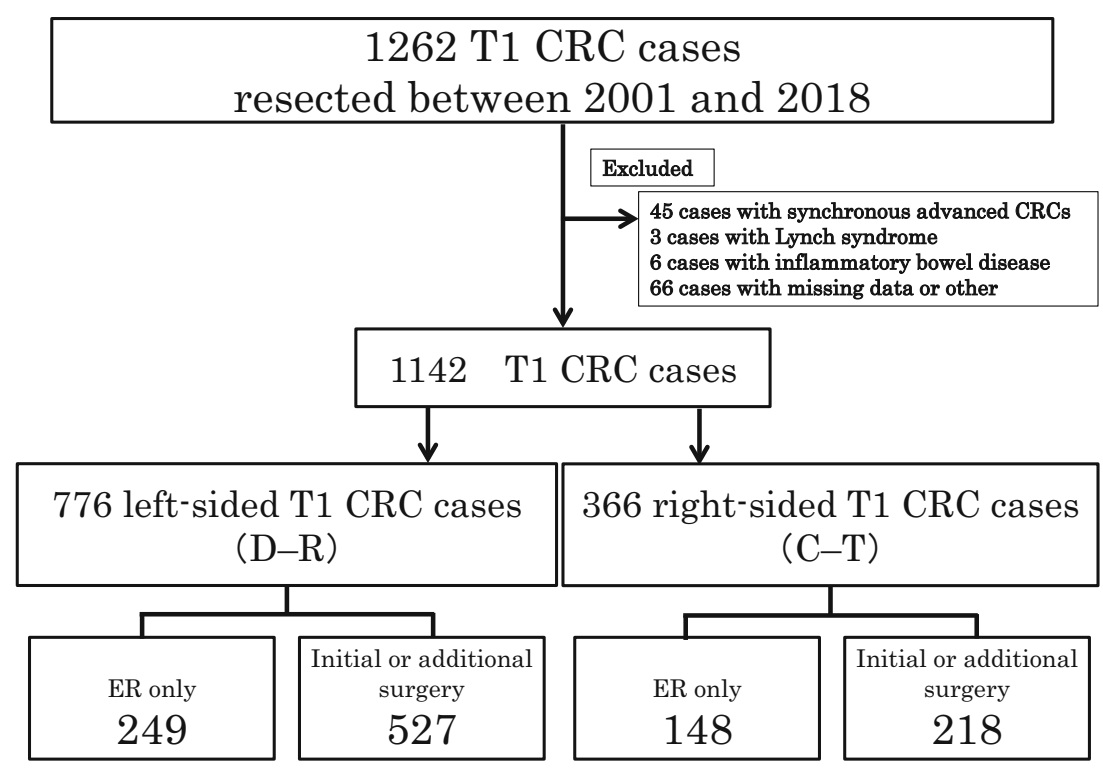


formalin fixation. All specimens were diagnosed based on the World Health Organization Classification of Tumors [18] and the current JSCCR (Japanese Society for Cancer of the Colon and Rectum) guidelines [19]. Histological grade was classified in view of the World Health Organization criteria as follows: well-differentiated adenocarcinoma, moderately differentiated adenocarcinoma, poorly differentiated adenocarcinoma (Por), and mucinous carcinoma (Muc). In this study, a Por/ Muc component was considered to be present if any part of the lesion contained any of these features. Vascular invasion was diagnosed by double staining with H\&E and Victoria blue (Muto Pure Chemicals Co., Ltd., Tokyo, Japan) and lymphatic invasion was diagnosed by $\mathrm{H} \& \mathrm{E}$ staining and immunostaining with D2-40 antibody (Dako North America Inc., Carpinteria, CA, USA). Tumor budding was defined as a cancer cell nest consisting of one to five cells at the invasive margin of the carcinoma. After selecting the field where budding was the most intensive, the number of buddings was counted with a $\times 20$ objective lens. Depending on the number of buddings, budding grade was scored as follows: BD1, 0-4; $\mathrm{BD} 2,5-9$; and BD3, $\geq 10$. BD 2-3 was defined as tumor budding-positive [20, 21]. The depth of submucosal invasion was assessed according to the JSCCR classification as < $1000 \mu \mathrm{m}$ (T1a) and $\geq 1000 \mu \mathrm{m}$ (T1b) [19].

\section{Statistical analysis}

Nominal and ordinal variables are expressed as frequencies and percentages. Continuous variables are reported as mean \pm standard deviation (SD). Continuous variables were compared using Student's $t$ tests, whereas dichotomous variables were compared using chi-squared or Fisher exact tests, as appropriate. Multivariate logistic regression analysis regarding LNM was subsequently performed to calculate odds ratios and $95 \%$ confidence intervals (CIs). All statistical analyses were performed using JMP Pro version 14.0.0 (SAS Institute Inc., Cary, NC, USA). All $P$ values were two sided, and $P<0.05$ was considered statistically significant.

\section{Results}

\section{Clinicopathological features of left- and right-sided T1 CRC}

The clinicopathological characteristics of 1142 patients are shown in Table 1. Table 2 shows the clinicopathological features of left- and right-sided T1 CRC. Left-sided T1 CRC showed significantly higher rates of LNM (left-sided $12.0 \%$ vs. right-sided $5.4 \%, P<0.05)$ and was accompanied by higher rates of lymphatic invasion (left-sided $32.7 \%$ vs. right-sided $23.2 \%, P<0.05)$ than right-sided T1 CRC. Leftsided T1 CRC also showed higher rates of T1b cases (leftsided $78.4 \%$ vs. right-sided $68.3 \%, P<0.05$ ) and surgical resections (left-sided $67.9 \%$ vs. right-sided $59.6 \%, P<0.05$ ). In morphology, left-sided T1 CRC showed significantly lower rates of flat type morphology (left-sided $27.6 \%$ vs. right-sided $53.0 \%, P<0.05)$. In contrast, the protruded type was significantly more frequent in left-sided T1 CRC (left-sided 51.2\% vs. right-sided $20.5 \%, P<0.05)$. For pathological features, left-sided T1 CRC showed significantly lower rates of Por/ Muc (left-sided $11.6 \%$ vs. right-sided 16.1\%, $P<0.05$ ). Patients with left-sided T1 CRC were younger (left-sided $64.9 \pm 11.5$ years vs. right-sided $68.7 \pm 11.6$ years, $P<0.05$ )
Table 1 Clinicopathological characteristics of the study patients $(n=1142)$

\begin{tabular}{|c|c|}
\hline Age (years) & $66.1 \pm 11.6$ \\
\hline Sex (male) & $723(63.3)$ \\
\hline Location (left-sided) & $776(68.0)$ \\
\hline Tumor size $(\mathrm{mm})$ & $21.5 \pm 13.6$ \\
\hline Morphology (flat type/protruded/depressed) & $408(35.7) / 472(41.3) / 262(22.9)$ \\
\hline Initial treatment (endoscopic resection) & $735(64.4)$ \\
\hline Treatment (surgical resection ${ }^{\mathrm{a}}$ ) & $745(65.2)$ \\
\hline Depth of invasion (T1b) & $858(75.1)$ \\
\hline Histological grade (Poror Muc ${ }^{\mathrm{b}}$ ) & $149(13.0)$ \\
\hline Vascular invasion (+) & $305(26.7)$ \\
\hline Lymphatic invasion $(+)$ & $339(29.7)$ \\
\hline Tumor budding (BD 2 or 3 ) & $236(20.7)$ \\
\hline Lymph node metastasis $(+)^{\mathrm{c}}$ & $75(10.1)$ \\
\hline
\end{tabular}

Results are expressed as mean \pm standard deviation or number of patients (\%), as appropriate

${ }^{\text {a }}$ Surgical resection: initial and additional surgical resection

${ }^{\mathrm{b}}$ Por or Muc, poorly differentiated adenocarcinoma or mucinous carcinoma

${ }^{\mathrm{c}}$ Includes only surgical cases. The denominator is the number of each surgery 
Table 2 Clinicopathological characteristics of patients with left- and right-sided T1 CRC

\begin{tabular}{|c|c|c|c|}
\hline & Left $(n=776)$ & Right $(n=366)$ & $P$ value \\
\hline Age (years) & $64.9 \pm 11.5$ & $68.7 \pm 11.6$ & $<0.05$ \\
\hline Sex (male) & $491(63.3)$ & $232(63.4)$ & 0.97 \\
\hline Tumor size (mm) & $21.0 \pm 14.2$ & $22.5 \pm 12.6$ & 0.08 \\
\hline Morphology (flat type/protruded/depressed) & $214(27.6) / 397(51.2) / 165(21.3)$ & $194(53.0) / 75(20.5) / 97(26.5)$ & $<0.05$ \\
\hline Initial treatment (endoscopic resection) & $510(65.7)$ & $225(61.5)$ & 0.16 \\
\hline Treatment (surgical resection ${ }^{\mathrm{a}}$ ) & $527(67.9)$ & $218(59.6)$ & $<0.05$ \\
\hline Depth of invasion (T1b) & $608(78.4)$ & $250(68.3)$ & $<0.05$ \\
\hline Histological grade (Por or $\mathrm{Muc}^{\mathrm{b}}$ ) & $90(11.6)$ & $59(16.1)$ & $<0.05$ \\
\hline Vascular invasion $(+)$ & $216(27.8)$ & $89(24.3)$ & 0.21 \\
\hline Lymphatic invasion $(+)$ & $254(32.7)$ & $85(23.2)$ & $<0.05$ \\
\hline Tumor budding (BD 2 or 3 ) & $171(22.3)$ & $65(17.8)$ & 0.10 \\
\hline Lymph node metastasis $(+)^{\mathrm{c}}(\mathrm{T} 1 \mathrm{a} / \mathrm{T} 1 \mathrm{~b})$ & $63(12.0)(5 / 58)$ & $12(5.4)(0 / 12)$ & $<0.05$ \\
\hline Local lymph node recurrence $(+)^{\mathrm{d}}(\mathrm{T} 1 \mathrm{a} / \mathrm{T} 1 \mathrm{~b})$ & $5(2.0)(1 / 4)$ & $0(0)(0 / 0)$ & 0.162 \\
\hline
\end{tabular}

Results are expressed as mean \pm standard deviation or number of patients (\%), as appropriate

${ }^{a}$ Surgical resection: initial and additional surgical resection

${ }^{\mathrm{b}}$ Por or Muc, poorly differentiated adenocarcinoma or mucinous carcinoma

${ }^{\mathrm{c}}$ Includes only surgical cases. The denominator is the number of each surgery

${ }^{\mathrm{d}}$ Includes only endoscopic resection cases. The denominator is the number of each endoscopic resection

than those with right-sided T1 CRC. No significant differences were found in the other factors.

Table 3 shows the clinicopathological features of left- and right-sided T1 CRC without the JSCCR guidelines' curative cases, which had one or more risk factors such as lymphovascular invasion, tumor budding, Por/Muc component, or T1b. Higher rates of initial endoscopic resection, lymphatic invasion, and LNM were evident in left-sided T1 CRC.

Table 3 Clinicopathological characteristics of patients with left- and right-sided T1 CRC without the Japanese guidelines' curative cases

\begin{tabular}{|c|c|c|c|}
\hline & Left $(n=652)$ & Right $(n=278)$ & $P$ value \\
\hline Age (years) & $64.9 \pm 11.5$ & $68.6 \pm 11.8$ & $<0.05$ \\
\hline Sex (male) & $409(62.7)$ & $166(59.7)$ & 0.39 \\
\hline Tumor size (mm) & $21.6 \pm 14.7$ & $22.2 \pm 12.3$ & 0.59 \\
\hline Morphology (flat type/protruded/depressed) & $167(25.6) / 329(50.5) / 156(23.9)$ & $127(45.7) / 62(22.3) / 89(32.0)$ & $<0.05$ \\
\hline Initial treatment (endoscopic resection) & $399(61.2)$ & $147(52.9)$ & $<0.05$ \\
\hline Treatment (surgical resection ${ }^{\mathrm{a}}$ ) & $509(78.1)$ & $206(74.1)$ & 0.19 \\
\hline Depth of invasion (T1b) & $606(92.9)$ & $250(89.9)$ & 0.12 \\
\hline Histological grade (Por or $\mathrm{Muc}^{\mathrm{b}}$ ) & $89(13.7)$ & $58(20.9)$ & $<0.05$ \\
\hline Vascular invasion (+) & $216(33.1)$ & $89(32.0)$ & 0.74 \\
\hline Lymphatic invasion (+) & $254(38.9)$ & $85(30.6)$ & $<0.05$ \\
\hline Tumor budding (BD 2 or 3 ) & $171(26.2)$ & $65(23.4)$ & 0.36 \\
\hline Lymph node metastasis $(+)^{\mathrm{c}}$ & $61(9.4)$ & $12(4.3)$ & $<0.05$ \\
\hline Local lymph node recurrence $(+)^{\mathrm{d}}(\mathrm{T} 1 \mathrm{a} / \mathrm{T} 1 \mathrm{~b})$ & $0(0)(0 / 0)$ & $0(0)(0 / 0)$ & $\mathrm{N} / \mathrm{A}$ \\
\hline
\end{tabular}

Results are expressed as mean \pm standard deviation or number of patients $(\%)$, as appropriate

$N / A$, not applicable

${ }^{\text {a }}$ Surgical resection: initial and additional surgical resection

${ }^{\mathrm{b}}$ Por or Muc, poorly differentiated adenocarcinoma or mucinous carcinoma

${ }^{\mathrm{c}}$ Includes only surgical cases. The denominator is the number of each surgery

${ }^{\mathrm{d}}$ Includes only endoscopic resection cases. The denominator is the number of each endoscopic resection 
Table 4 Clinicopathological characteristics of T1 CRC according to each location

\begin{tabular}{|c|c|c|c|c|c|c|}
\hline & $\mathrm{C}(n=61)$ & $\mathrm{A}(n=168)$ & $\mathrm{T}(n=137)$ & $\mathrm{D}(n=49)$ & $\mathrm{S}(n=516)$ & $\mathrm{R}(n=211)$ \\
\hline Age (years) & $68.8 \pm 11.2$ & $68.7 \pm 11.5$ & $68.6 \pm 11.9$ & $68.6 \pm 12.9$ & $64.9 \pm 11.2$ & $63.9 \pm 11.5$ \\
\hline Sex (male) & $32(52.5)$ & $108(64.3)$ & $92(67.2)$ & $35(71.4)$ & $322(62.4)$ & $134(63.5)$ \\
\hline Tumor size (mm) & $26.3 \pm 11.4$ & $22.8 \pm 14.0$ & $20.6 \pm 11.0$ & $20.0 \pm 9.8$ & $19.0 \pm 10.8$ & $26.2 \pm 19.8$ \\
\hline \multicolumn{7}{|l|}{ Morphology } \\
\hline Flat type & $32(52.5)$ & $88(52.4)$ & $74(54.0)$ & $26(53.1)$ & $108(20.9)$ & $80(37.9)$ \\
\hline Protruded type & $17(27.9)$ & $34(20.2)$ & $24(17.5)$ & $18(36.7)$ & $302(58.5)$ & $77(36.5)$ \\
\hline Depressed type & $12(19.7)$ & $46(27.4)$ & $39(28.5)$ & $5(10.2)$ & $106(20.5)$ & $54(25.6)$ \\
\hline Initial treatment (endoscopic resection) & $38(62.3)$ & $101(60.1)$ & $86(62.8)$ & $34(69.4)$ & $352(68.2)$ & $124(58.8)$ \\
\hline Treatment (surgical resection ${ }^{\mathrm{a}}$ ) & $38(62.3)$ & $104(61.9)$ & $76(55.5)$ & $23(46.9)$ & $363(70.3)$ & $141(66.8)$ \\
\hline Depth of invasion (T1b) & $43(70.5)$ & $119(70.8)$ & $88(64.2)$ & $29(59.2)$ & $401(77.7)$ & $178(84.4)$ \\
\hline Histological grade (Por or $\mathrm{Muc}^{\mathrm{b}}$ ) & $12(19.7)$ & $22(13.1)$ & $25(18.2)$ & $2(4.1)$ & $63(12.2)$ & $25(11.8)$ \\
\hline Vascular invasion $(+)$ & $13(21.3)$ & $43(25.6)$ & $33(24.1)$ & $5(10.2)$ & $129(25.0)$ & $82(38.9)$ \\
\hline Lymphatic invasion (+) & $14(23.0)$ & $38(22.6)$ & $33(24.1)$ & $8(16.3)$ & $169(32.8)$ & $77(36.5)$ \\
\hline Tumor budding (BD 2 or 3 ) & $10(16.4)$ & $32(19.0)$ & $23(16.8)$ & $7(14.3)$ & $114(22.1)$ & $50(23.7)$ \\
\hline Lymph node metastasis $(+)^{\mathrm{c}}$ & $2 / 38(5.3)$ & $4 / 104(3.8)$ & $6 / 76(7.9)$ & $1 / 23(4.3)$ & $45 / 363(12.4)$ & $17 / 141(12.1)$ \\
\hline Local lymph node recurrence $(+)^{\mathrm{d}}$ & $0 / 23(0)$ & $0 / 64(0)$ & $0 / 61(0)$ & $0 / 26(0)$ & $1 / 153(0.7)$ & $4 / 70(5.7)$ \\
\hline
\end{tabular}

Results are expressed as mean \pm standard deviation or number of patients $(\%)$, as appropriate

$C$, cecum; $A$, ascending colon; $T$, transverse colon, $D$, descending colon; $S$, sigmoid colon; $R$, rectum

${ }^{\text {a }}$ Surgical resection: initial and additional surgical resection

${ }^{\mathrm{b}}$ Por or Muc, poorly differentiated adenocarcinoma or mucinous carcinoma

${ }^{\mathrm{c}}$ Includes only surgical cases. The denominator is the number of each surgery

${ }^{\mathrm{d}}$ Includes only endoscopic resection cases. The denominator is the number of each endoscopic resection

We also compared the differences in clinicopathological features by each location in Table 4 . The sigmoid colon and rectum showed higher positive rates of lymphatic invasion and tumor budding than other sites. The rectum also showed the highest rate of vascular invasion (38.9\%). Patients' age was younger in sigmoid $(64.9 \pm 11.2)$ and rectum $(63.9 \pm$ 11.5) T1 CRC. Fewer cases were operated upon in the descending colon (46.9\%), whereas more cases were operated upon in the sigmoid and rectum $(70.3 \%$ and $66.8 \%$, respectively). T1 CRC of the sigmoid colon and rectum showed a higher rate of LNM (12.4\% and $12.1 \%)$ than other sites. The frequency of LNM with each morphology at both locations is shown in Table 5. Sigmoid lesions of the depressed type showed the highest percentage of LNM (13.2\%).

Table 6 shows the relationships between clinicopathological factors and LNM identified by univariate and multivariate
Table 5 LNM or LNR according to each location

\begin{tabular}{lllllll}
\hline & $\mathrm{C}(n=61)$ & $\mathrm{A}(n=168)$ & $\mathrm{T}(n=137)$ & $\mathrm{D}(n=49)$ & $\mathrm{S}(n=516)$ & $\mathrm{R}(n=211)$ \\
\hline Flat type & & & & & & \\
LNM $(+)^{\mathrm{a}}$ & $1 / 32(3.1)$ & $1 / 88(1.1)$ & $1 / 74(1.4)$ & $0 / 26(0)$ & $6 / 108(5.6)$ & $5 / 80(6.3)$ \\
LNR $(+)^{\mathrm{b}}$ & $0 / 15(0)$ & $0 / 45(0)$ & $0 / 46(0)$ & $0 / 14(0)$ & $0 / 43(0)$ & $2 / 40(5.0)$ \\
Protruded type & & & & & & \\
LNM $(+)^{\mathrm{a}}$ & $1 / 17(5.9)$ & $2 / 34(5.9)$ & $2 / 24(8.3)$ & $1 / 18(5.6)$ & $25 / 302(8.3)$ & $8 / 77(10.4)$ \\
LNR $(+)^{\mathrm{b}}$ & $0 / 7(0)$ & $0 / 13(0)$ & $0 / 9(0)$ & $0 / 11(0)$ & $1 / 99(1.0)$ & $0 / 23(0)$ \\
Depressed type & & & & & & \\
LNM $(+)^{\mathrm{a}}$ & $0 / 12(0)$ & $1 / 46(2.2)$ & $3 / 39(7.7)$ & $0 / 5(0)$ & $14 / 106(13.2)$ & $4 / 54(7.4)$ \\
LNR $(+)^{\mathrm{b}}$ & $0 / 1(0)$ & $0 / 6(0)$ & $0 / 6(0)$ & $0 / 1(0)$ & $0 / 11(0)$ & $2 / 7(28.6)$ \\
\hline
\end{tabular}

Results are expressed as number of patients (\%)

$C$, cecum; $A$, ascending colon; $T$, transverse colon; $D$, descending colon; $S$, sigmoid colon; $R$, rectum; $L N M$, lymph node metastasis; $L N R$, local lymph node recurrence

${ }^{a}$ Includes only surgical cases. The denominator is the number of each surgery

${ }^{\mathrm{b}}$ Includes only endoscopic resection cases. The denominator is the number of each endoscopic resection 
Table 6 Relationships between clinicopathological factors and LNM

\begin{tabular}{|c|c|c|c|c|c|}
\hline & \multicolumn{3}{|c|}{ Univariate analysis } & \multicolumn{2}{|c|}{ Multivariate analysis } \\
\hline & $\mathrm{LNM}+(n=75)$ & $\mathrm{LNM}^{-}(n=670)$ & $P$ value & OR $(95 \% \mathrm{CI})$ & $P$ value \\
\hline Age $(<70)$ & $47(62.7)$ & $413(61.6)$ & 0.86 & $0.84(0.50-1.43)$ & 0.53 \\
\hline Sex (male) & $38(81.3)$ & $422(63.0)$ & $<0.05$ & $0.57(0.34-0.97)$ & $<0.05$ \\
\hline Tumor size $(\geq 20 \mathrm{~mm})$ & $40(53.3)$ & $326(48.7)$ & 0.44 & $1.25(0.71-2.20)$ & 0.43 \\
\hline Location (left) & $63(84.0)$ & $464(69.3)$ & $<0.05$ & $2.42(1.23-4.78)$ & $<0.05$ \\
\hline Morphology (depressed type) & $22(29.3)$ & $208(31.0)$ & 0.76 & $0.78(0.39-1.57)$ & 0.49 \\
\hline Initial treatment (endoscopic resection) & $37(49.3)$ & $304(45.4)$ & 0.51 & $0.94(0.51-1.71)$ & 0.83 \\
\hline Depth of invasion (T1b) & $70(93.3)$ & $619(92.4)$ & 0.77 & $0.74(0.26-2.12)$ & 0.57 \\
\hline Histological grade (Por or Muc ${ }^{\mathrm{a}}$ ) & $21(28.0)$ & $102(15.2)$ & $<0.05$ & $2.08(1.13-3.81)$ & $<0.05$ \\
\hline Lymphovascular invasion (+) & $71(94.7)$ & $350(52.2)$ & $<0.05$ & $15.5(5.47-44.1)$ & $<0.05$ \\
\hline Tumor budding (BD 2 or 3 ) & $38(50.7)$ & $168(25.1)$ & $<0.05$ & $1.64(0.97-2.79)$ & 0.07 \\
\hline
\end{tabular}

Results are expressed as number of patients (\%)

$L N M$, lymph node metastasis; $O R$, odds ratio; $C I$, confidence interval

${ }^{a}$ Por or Muc, poorly differentiated adenocarcinoma or mucinous carcinoma

logistic analyses. Left-sided location was an independent risk factor for LNM (OR, 2.42; 95\% CI, 1.23-4.78). Furthermore, lymphovascular invasion, histological grade, and sex were independent risk factors for LNM in T1 CRC.

Figure 2 shows images of a typical left-sided T1 CRC case, demonstrating its lymphovascular invasion-positive, tumor budding-positive, and LNM-positive features.

\section{Discussion}

In this study, we compared the clinicopathological features of left-sided T1 CRC with right-sided CRC. Left-sided T1 CRC had a significantly higher rate of lymphatic invasion and LNM. More careful management would be required for leftsided T1 CRC when determining the need for additional surgery after endoscopic resection.

We focused on T1 CRC and revealed that the left-sided location was a risk factor for LNM in T1 CRC. One reason that the clinicopathological features differed by location may be anatomical and genetic differences. The gastrointestinal tract is derived from the endoderm, from which the left colon is derived from the hindgut, while the right colon is derived from the midgut. In advanced cancer, some studies reported the following differences between left- and right-sided CRC. Left-sided CRC patients have a better PFS (progression-free survival), OS (overall survival), and ORR (overall response rate) than right-sided CRC patients. As a histological grade, there are lower rates of mucinous carcinomas, and these express a serrated pathway signature in left-sided CRC. Leftsided CRC was present in a lower percentage of female and had multiple metastatic sites. However, most of these studies investigated advanced $\mathrm{CRC}$, and there is no obvious mechanism regarding these differences in early-stage disease. Similar to advanced CRC, younger age and a lower rate of Por/Muc were observed in left-sided T1 CRC. In this study, the positive rate of lymphatic invasion was high in the left side, suggesting that this may be a factor in the high rate of LNM in left-sided T1 CRC.

There have been various studies regarding the risk of LNM [22-26]. Lymphovascular invasion and histological grade are described in guidelines from the USA, Europe, and Japan [19, 27-30]. Furthermore, in Europe and Japan, the degree of SM invasion and in Japan, budding grade are described as risk factors. In addition, female sex and the status of the muscularis mucosae were also reported as risk factors [22, 31-33]. Regarding location, there have been several reports comparing the rectum and colon, which showed that the rate of LNM was equivalent or higher in the rectum $[15,16]$. The current study dividing the tumor location into the left- and right-side is the largest study of T1 CRC. As a result, the left-sided location

Fig. 2 A typical case of left-sided T1 CRC. a A 15-mm-sized lesion of erythematous color was viewed by white light observation. This lesion was located in the sigmoid colon. b During indigo carmine spray observation, the dye accumulated in the circumferential grooved margin. The lesion was diagnosed as IIa+IIc due to the margin of depression. c In magnified observation with crystal violet staining, non-structure area was found around irregular pits and it was diagnosed as $V_{\mathrm{N}}$ type pit pattern. Initial laparoscopic-assisted surgery was performed. d Histology of this lesion by HE staining. The infiltrative advanced region had a fused tubular structure, and the worst histological diagnosis was moderately differentiated adenocarcinoma. e Tumor budding was evident in HE staining. f Histology of the lesion by D2-40 staining. Lymphatic invasion was evident. $\mathrm{g}$ Histology of the lesion by Victoria Blue staining. Vascular invasion was apparent. h Histology of metastatic lymph nodes by HE staining. The pathological diagnosis was T1 carcinoma (SM $2375 \mu \mathrm{m}$ ), type IIa+IIc, $19 \mathrm{~mm}$, papillary and well-to-moderately differentiated adenocarcinoma, ly1, v1, BD2, pN1 
(a)

(d)

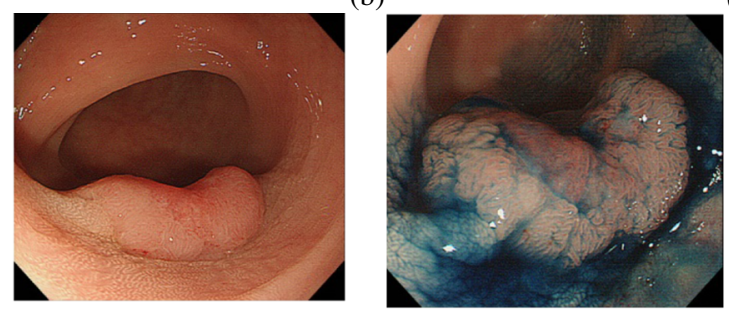

(c)

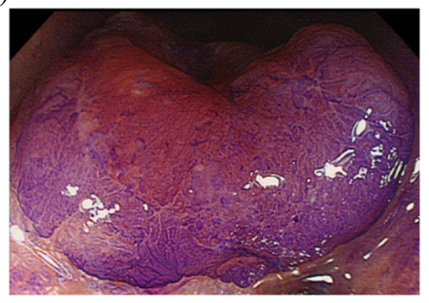

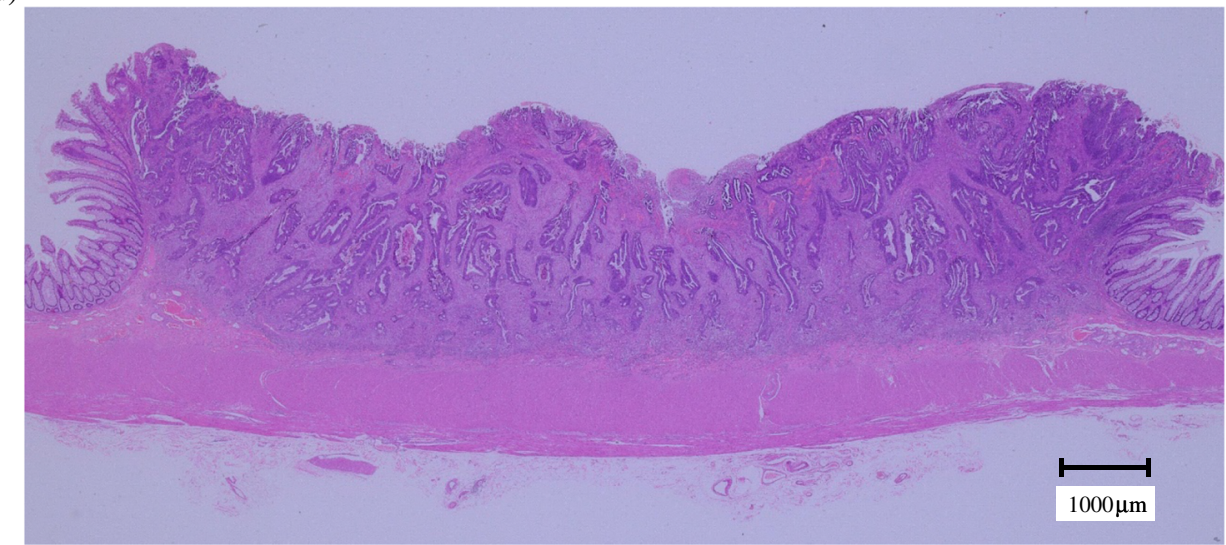

(e)

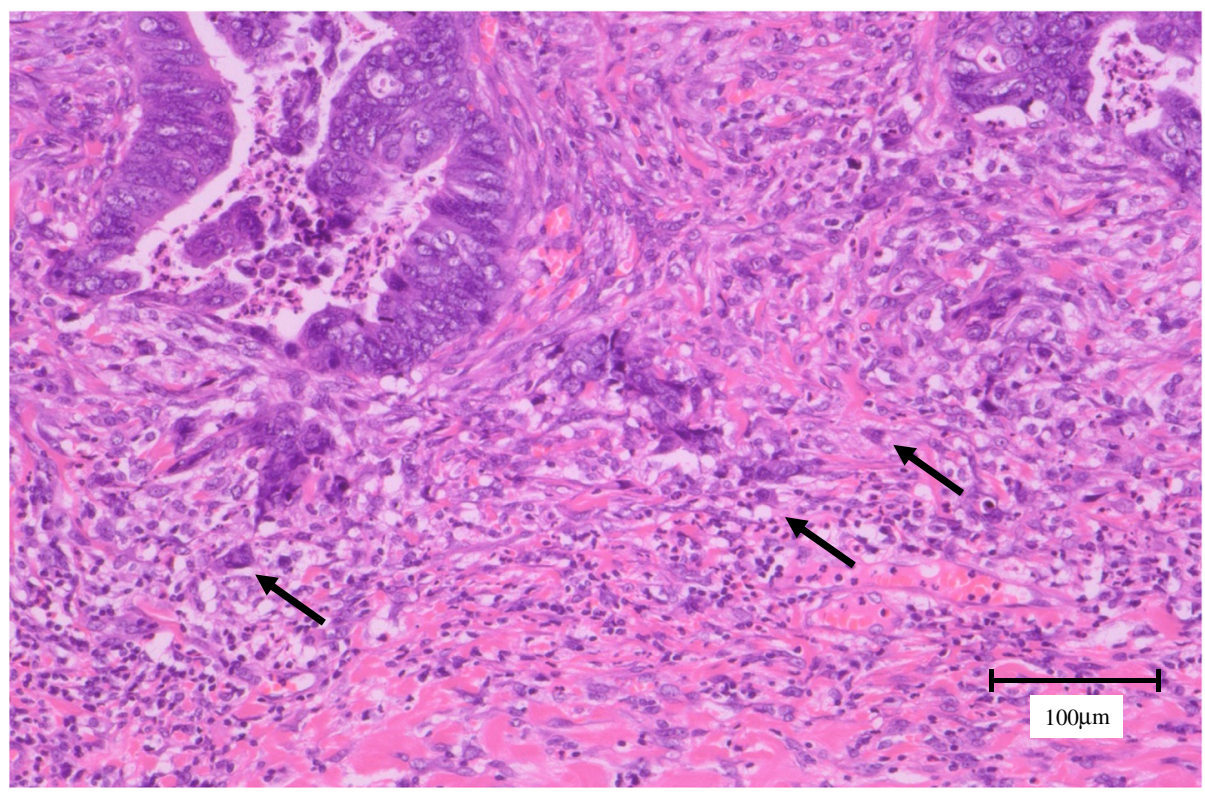

(g)

(f)

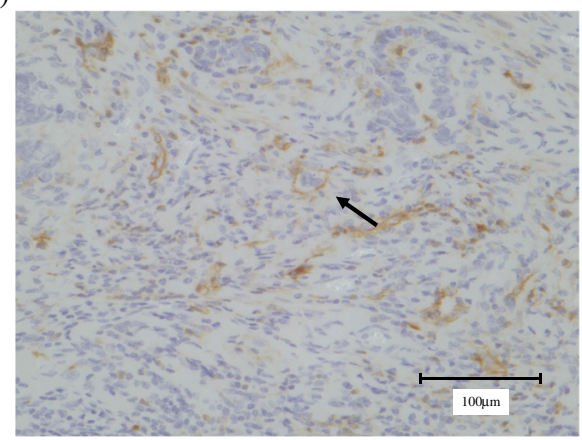

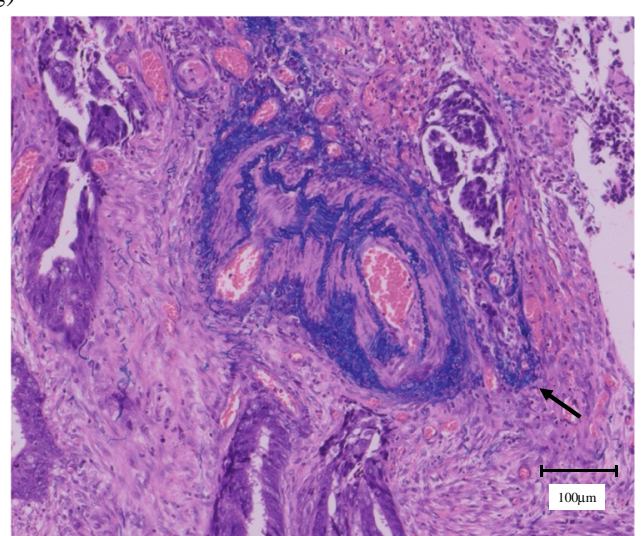


was an independent risk factor for LNM. Especially, the positive rate of LNM was highest in the sigmoid colon (12.4\%) and rectum $(12.1 \%)$, whereas the descending colon showed $4.3 \%$ LNM. Loree et al. reported characteristics that differed by location among left-sided sites. For example, many descending colon features appear more "right-sided." There was a higher proportion of mucinous histology in the descending colon (24\%) compared with the sigmoid (14\%) and rectosigmoid junction (12\%) [34]. These features suggest that while the descending colon is classified on the left, it may be closer to the right-sided colon. In any case, the results of our study suggested that tumor location should be considered when determining the need for additional surgery after endoscopic resection of T1 CRC.

The present study had several limitations. First, this was a retrospective analysis based on clinical records. Regarding LNM in patients treated by endoscopic resection alone, we used the findings of CT or MRI instead. However, our cohort was one of the largest single-center studies of T1 CRC. Second, the statistical power might be insufficient to reveal small differences in each tumor location subgroup analysis. Third, the pathological diagnosis of the included patients was not re-evaluated. A large-scale multicenter study is needed to verify the clinicopathological features of left- and right-sided CRC revealed in this study.

In conclusion, this study indicated that left-sided T1 CRC, especially that in the sigmoid colon and rectum, shows higher rates of LNM than right-sided T1 CRC, followed by higher rates of lymphatic invasion. These results suggested that leftsided T1 CRC should be considered different diseases that require different forms of management.

\section{Compliance with ethical standards}

Written informed consent was obtained from all the patients prior to endoscopy. Our ethics committee approved the study protocol (approval number: 17H107).

Open Access This article is licensed under a Creative Commons Attribution 4.0 International License, which permits use, sharing, adaptation, distribution and reproduction in any medium or format, as long as you give appropriate credit to the original author(s) and the source, provide a link to the Creative Commons licence, and indicate if changes were made. The images or other third party material in this article are included in the article's Creative Commons licence, unless indicated otherwise in a credit line to the material. If material is not included in the article's Creative Commons licence and your intended use is not permitted by statutory regulation or exceeds the permitted use, you will need to obtain permission directly from the copyright holder. To view a copy of this licence, visit http://creativecommons.org/licenses/by/4.0/.

\section{References}

1. Katanoda K, Hori M, Matsuda T, Shibata A, Nishino Y, Hattori M, Soda M, Ioka A, Sobue T, Nishimoto H (2015) An updated report on the trends in cancer incidence and mortality in Japan, 1958-
2013. Jpn J Clin Oncol 45(4):390-401. https://doi.org/10.1093/ jjco/hyv002

2. Bray F, Ferlay J, Soerjomataram I, Siegel RL, Torre LA, Jemal A (2018) Global cancer statistics 2018: GLOBOCAN estimates of incidence and mortality worldwide for 36 cancers in 185 countries. CA Cancer J Clin 68(6):394-424. https://doi.org/10.3322/caac. 21492

3. He WZ, Liao FX, Jiang C, Kong PF, Yin CX, Yang Q, Qiu HJ, Zhang B, Xia LP (2017) Primary tumor location as a predictive factor for first-line bevacizumab effectiveness in metastatic colorectal cancer patients. J Cancer 8(3):388-394. https://doi.org/10.7150/ jca. 16804

4. Meguid RA, Slidell MB, Wolfgang CL, Chang DC, Ahuja N (2008) Is there a difference in survival between right- versus leftsided colon cancers? Ann Surg Oncol 15(9):2388-2394. https://doi. org/10.1245/s10434-008-0015-y

5. Weiss JM, Pfau PR, O'Connor ES, King J, LoConte N, Kennedy G, Smith MA (2011) Mortality by stage for right- versus left-sided colon cancer: analysis of surveillance, epidemiology, and end results-Medicare data. J Clin Oncol 29(33):4401-4409. https:// doi.org/10.1200/JCO.2011.36.4414

6. Salem ME, Weinberg BA, Xiu J, El-Deiry WS, Hwang JJ, Gatalica Z, Philip PA, Shields AF, Lenz HJ, Marshall JL (2017) Comparative molecular analyses of left-sided colon, right-sided colon, and rectal cancers. Oncotarget 8(49):86356-86368. https://doi. org/10.18632/oncotarget.21169

7. Petrelli F, Tomasello G, Borgonovo K, Ghidini M, Turati L, Dallera P, Passalacqua R, Sgroi G, Barni S (2017) Prognostic survival associated with left-sided vs right-sided colon cancer: a systematic review and meta-analysis. JAMA Oncol 3(2):211-219. https://doi. org/10.1001/jamaoncol.2016.4227

8. Kamran SC, Clark JW, Zheng H, Borger DR, Blaszkowsky LS, Allen JN, Kwak EL, Wo JY, Parikh AR, Nipp RD, Murphy JE, Goyal L, Zhu AX, Iafrate AJ, Corcoran RB, Ryan DP, Hong TS (2018) Primary tumor sidedness is an independent prognostic marker for survival in metastatic colorectal cancer: results from a large retrospective cohort with mutational analysis. Cancer Med 7:2934 2942. https://doi.org/10.1002/cam4.1558

9. Tran B, Kopetz S, Tie J, Gibbs P, Jiang ZQ, Lieu CH, Agarwal A, Maru DM, Sieber O, Desai J (2011) Impact of BRAF mutation and microsatellite instability on the pattern of metastatic spread and prognosis in metastatic colorectal cancer. Cancer 117(20):46234632. https://doi.org/10.1002/cncr.26086

10. Caiazza F, Ryan EJ, Doherty G, Winter DC, Sheahan K (2015) Estrogen receptors and their implications in colorectal carcinogenesis. Front Oncol 5:19. https://doi.org/10.3389/fonc.2015.00019

11. Hendifar A, Yang D, Lenz F, Lurje G, Pohl A, Lenz C, Ning Y, Zhang W, Lenz HJ (2009) Gender disparities in metastatic colorectal cancer survival. Clin Cancer Res 15(20):6391-6397. https://doi. org/10.1158/1078-0432.CCR-09-0877

12. Slattery ML, Potter JD, Curtin K, Edwards S, Ma KN, Anderson K, Schaffer D, Samowitz WS (2001) Estrogens reduce and withdrawal of estrogens increase risk of microsatellite instability-positive colon cancer. Cancer Res 61(1):126-130

13. Cancer Genome Atlas N (2012) Comprehensive molecular characterization of human colon and rectal cancer. Nature 487(7407):330 337. https://doi.org/10.1038/nature11252

14. Frattini M, Balestra D, Suardi S, Oggionni M, Alberici P, Radice P, Costa A, Daidone MG, Leo E, Pilotti S, Bertario L, Pierotti MA (2004) Different genetic features associated with colon and rectal carcinogenesis. Clin Cancer Res 10(12 Pt 1):4015-4021. https:// doi.org/10.1158/1078-0432.CCR-04-0031

15. Ichimasa K, Kudo SE, Miyachi H, Kouyama Y, Hayashi T, Wakamura K, Hisayuki T, Kudo T, Misawa M, Mori Y, Matsudaira S, Hidaka E, Hamatani S, Ishida F (2017) Comparative clinicopathological characteristics of colon and rectal 
T1 carcinoma. Oncol Lett 13(2):805-810. https://doi.org/10.3892/ ol.2016.5464

16. Nascimbeni R, Burgart LJ, Nivatvongs S, Larson DR (2002) Risk of lymph node metastasis in T1 carcinoma of the colon and rectum. Dis Colon Rectum 45(2):200-206. https://doi.org/10.1007/s10350004-6147-7

17. Kudo S, Lambert R, Allen JI, Fujii H, Fujii T, Kashida H, Matsuda T, Mori M, Saito H, Shimoda T, Tanaka S, Watanabe H, Sung JJ, Feld AD, Inadomi JM, O'Brien MJ, Lieberman DA, Ransohoff DF, Soetikno RM, Triadafilopoulos G, Zauber A, Teixeira CR, Rey JF, Jaramillo E, Rubio CA, Van Gossum A, Jung M, Vieth M, Jass JR, Hurlstone PD (2008) Nonpolypoid neoplastic lesions of the colorectal mucosa. Gastrointest Endosc 68(4 Suppl):S3-S47. https:// doi.org/10.1016/j.gie.2008.07.052

18. Nagtegaal ID, Odze RD, Klimstra D, Paradis V, Rugge M, Schirmacher P, Washington KM, Carneiro F, Cree IA, Board WHOCoTE (2020) The 2019 WHO classification of tumours of the digestive system. Histopathology 76(2):182-188. https://doi. org/10.1111/his.13975

19. Hashiguchi Y, Muro K, Saito Y, Ito Y, Ajioka Y, Hamaguchi T, Hasegawa K, Hotta K, Ishida H, Ishiguro M, Ishihara S, Kanemitsu Y, Kinugasa Y, Murofushi K, Nakajima TE, Oka S, Tanaka T, Taniguchi H, Tsuji A, Uehara K, Ueno H, Yamanaka T, Yamazaki K, Yoshida M, Yoshino T, Itabashi M, Sakamaki K, Sano K, Shimada Y, Tanaka S, Uetake H, Yamaguchi S, Yamaguchi N, Kobayashi H, Matsuda K, Kotake K, Sugihara K, Japanese Society for Cancer of the C, Rectum (2020) Japanese Society for Cancer of the Colon and Rectum (JSCCR) guidelines 2019 for the treatment of colorectal cancer. Int J Clin Oncol 25(1): 1-42. https://doi.org/10.1007/s10147-019-01485-Z

20. Ueno H, Mochizuki H, Hashiguchi Y, Shimazaki H, Aida S, Hase K, Matsukuma S, Kanai T, Kurihara H, Ozawa K, Yoshimura K, Bekku S (2004) Risk factors for an adverse outcome in early invasive colorectal carcinoma. Gastroenterology 127(2):385-394. https://doi.org/10.1053/j.gastro.2004.04.022

21. Ueno H, Murphy J, Jass JR, Mochizuki H, Talbot IC (2002) Tumour 'budding' as an index to estimate the potential of aggressiveness in rectal cancer. Histopathology 40(2):127-132. https:// doi.org/10.1046/j.1365-2559.2002.01324.x

22. Miyachi H, Kudo SE, Ichimasa K, Hisayuki T, Oikawa H, Matsudaira S, Kouyama Y, Kimura YJ, Misawa M, Mori Y, Ogata N, Kudo T, Kodama K, Hayashi T, Wakamura K, Katagiri A, Baba T, Hidaka E, Ishida F, Kohashi K, Hamatani S (2016) Management of T1 colorectal cancers after endoscopic treatment based on the risk stratification of lymph node metastasis. J Gastroenterol Hepatol 31(6):1126-1132. https://doi.org/10.1111/ jgh. 13257

23. Ichimasa K, Kudo SE, Mori Y, Misawa M, Matsudaira S, Kouyama Y, Baba T, Hidaka E, Wakamura K, Hayashi T, Kudo T, Ishigaki T, Yagawa Y, Nakamura H, Takeda K, Haji A, Hamatani S, Mori K, Ishida F, Miyachi H (2018) Artificial intelligence may help in predicting the need for additional surgery after endoscopic resection of T1 colorectal cancer. Endoscopy 50(3):230-240. https://doi.org/ $10.1055 / \mathrm{s}-0043-122385$

24. Yasue C, Chino A, Takamatsu M, Namikawa K, Ide D, Saito S, Igarashi M, Fujisaki J (2019) Pathological risk factors and predictive endoscopic factors for lymph node metastasis of $\mathrm{T} 1$ colorectal cancer: a single-center study of 846 lesions. J Gastroenterol 54(8): 708-717. https://doi.org/10.1007/s00535-019-01564-y

25. Backes Y, de Vos Tot Nederveen Cappel WH, van Bergeijk J, Ter Borg F, Schwartz MP, BWM S, JMJ G, Kessels K, Kerkhof M, Groen JN, FHJ W, TCJ S, van Lelyveld N, GJA O, Siersema PD, Lacle MM, Moons LMG (2017) Risk for incomplete resection after macroscopic radical endoscopic resection of $\mathrm{T} 1$ colorectal cancer: a multicenter cohort study. Am J Gastroenterol 112(5):785-796. https://doi.org/10.1038/ajg.2017.58

26. Suh JH, Han KS, Kim BC, Hong CW, Sohn DK, Chang HJ, Kim MJ, Park SC, Park JW, Choi HS, Oh JH (2012) Predictors for lymph node metastasis in T1 colorectal cancer. Endoscopy 44(6): 590-595. https://doi.org/10.1055/s-0031-1291665

27. Benson AB 3rd, Venook AP, Cederquist L, Chan E, Chen YJ, Cooper HS, Deming D, Engstrom PF, Enzinger PC, Fichera A, Grem JL, Grothey A, Hochster HS, Hoffe S, Hunt S, Kamel A, Kirilcuk N, Krishnamurthi S, Messersmith WA, Mulcahy MF, Murphy JD, Nurkin S, Saltz L, Sharma S, Shibata D, Skibber JM, Sofocleous CT, Stoffel EM, Stotsky-Himelfarb E, Willett CG, Wu CS, Gregory KM, Freedman-Cass D (2017) Colon cancer, version 1.2017, NCCN Clinical Practice Guidelines in Oncology. J Natl Compr Canc Netw 15(3):370-398. https://doi.org/10.6004/jnccn. 2017.0036

28. Benson AB, Venook AP, Al-Hawary MM, Cederquist L, Chen YJ, Ciombor KK, Cohen S, Cooper HS, Deming D, Engstrom PF, Grem JL, Grothey A, Hochster HS, Hoffe S, Hunt S, Kamel A, Kirilcuk N, Krishnamurthi S, Messersmith WA, Meyerhardt J, Mulcahy MF, Murphy JD, Nurkin S, Saltz L, Sharma S, Shibata D, Skibber JM, Sofocleous CT, Stoffel EM, Stotsky-Himelfarb E, Willett CG, Wuthrick E, Gregory KM, Gurski L, Freedman-Cass DA (2018) Rectal cancer, version 2.2018, NCCN Clinical Practice Guidelines in Oncology. J Natl Compr Cancer Netw 16(7):874 901. https://doi.org/10.6004/jnccn.2018.0061

29. Labianca R, Nordlinger B, Beretta GD, Mosconi S, Mandala M, Cervantes A, Arnold D, Group EGW (2013) Early colon cancer: ESMO clinical practice guidelines for diagnosis, treatment and follow-up. Ann Oncol 24 Suppl 6:vi64-72. doi:https://doi.org/10. 1093/annonc/mdt354

30. Glimelius B, Tiret E, Cervantes A, Arnold D, Group EGW (2013) Rectal cancer: ESMO clinical practice guidelines for diagnosis, treatment and follow-up. Ann Oncol 24(Suppl 6):vi81-vi88. https://doi.org/10.1093/annonc/mdt240

31. Nakadoi K, Oka S, Tanaka S, Hayashi N, Terasaki M, Arihiro K, Shimamoto F, Chayama K (2014) Condition of muscularis mucosae is a risk factor for lymph node metastasis in T1 colorectal carcinoma. Surg Endosc 28(4):1269-1276. https://doi.org/10.1007/ s00464-013-3321-9

32. Kitajima K, Fujimori T, Fujii S, Takeda J, Ohkura Y, Kawamata H, Kumamoto T, Ishiguro S, Kato Y, Shimoda T, Iwashita A, Ajioka Y, Watanabe H, Watanabe T, Muto T, Nagasako K (2004) Correlations between lymph node metastasis and depth of submucosal invasion in submucosal invasive colorectal carcinoma: a Japanese collaborative study. J Gastroenterol 39(6):534-543. https://doi.org/10.1007/s00535-004-1339-4

33. Ichimasa K, Kudo SE, Miyachi H, Kouyama Y, Ishida F, Baba T, Katagiri A, Wakamura K, Hayashi T, Hisayuki T, Kudo T, Misawa M, Mori Y, Matsudaira S, Kimura Y, Kataoka Y (2017) Patient gender as a factor associated with lymph node metastasis in T1 colorectal cancer: a systematic review and meta-analysis. Mol Clin Oncol 6(4):517-524. https://doi.org/10.3892/mco.2017.1172

34. Loree JM, Pereira AAL, Lam M, Willauer AN, Raghav K, Dasari A, Morris VK, Advani S, Menter DG, Eng C, Shaw K, Broaddus R, Routbort MJ, Liu Y, Morris JS, Luthra R, Meric-Bernstam F, Overman MJ, Maru D, Kopetz S (2018) Classifying colorectal cancer by tumor location rather than sidedness highlights a continuum in mutation profiles and consensus molecular subtypes. Clin Cancer Res 24(5):1062-1072. https://doi.org/10.1158/1078-0432.CCR$17-2484$

Publisher's note Springer Nature remains neutral with regard to jurisdictional claims in published maps and institutional affiliations. 